\title{
Esclarecimento sobre tipos de artigos científicos para publicação na Revista de Ciências Agroveterinárias
}

\section{Leonardo Bianco de Carvalho}

Em decorrência de diversos questionamentos e dificuldades de alguns autores em entender a diferença entre artigo completo e nota científica, bem como o que é um artigo de revisão, o objetivo desta nota editorial é esclarecer aos editores, autores e leitores da Revista de Ciências Agroveterinárias a respeito dos tipos de artigos que são publicados nesta revista. Inclui-se, ainda, que esta revista passará a padronizar os tipos de artigo, a partir de 2018, como Artigo de Pesquisa (artigo completo), Nota de Pesquisa (nota científica) e Artigo de Revisão (revisão de literatura). Além disso, esta revista publica comunicações dos editores como Nota Editorial.

Os três tipos de artigos publicados pela revista, Artigo de Pesquisa, Nota de Pesquisa e Artigo de Revisão, são artigos científicos derivados de pesquisa realizada pelos autores. Artigos de pesquisa e notas de pesquisa são derivados, em geral, de pesquisa experimental original e, portanto, baseados em resultados obtidos experimentalmente pelos autores. Artigos de revisão são derivados de pesquisa não experimental, ou seja, não baseadas em resultados obtidos experimentalmente, mas sim baseadas no conhecimento (resultados e conclusões) gerado até o momento sobre determinado assunto.

Artigo de pesquisa e nota de pesquisa são, portanto, similares segundo sua base empírica. No entanto, há diferenças entre estes dois tipos de artigos que vão além da extensão do texto. Notas de pesquisa são textos breves, curtos, com volume pequeno de resultados, mas que geram conclusão(ões) inédita(s) em decorrência de um fato novo descoberto pelos autores. Dessa maneira, sua publicação é justificada devido à importância da descoberta, ou seja, do conhecimento científico gerado, mesmo não havendo grande volume de resultados. Artigos de pesquisa são, por sua vez, textos mais longos, com maior volume de resultados, que também geram conclusões inéditas em decorrência de novas descobertas científicas. Portanto, deve-se ficar claro que artigos de pesquisa e notas de pesquisa apresentam igual importância na construção do conhecimento científico.

Assim, um artigo com pequeno volume de resultados, em que os autores incrementam as informações da introdução e da discussão, com intuito de aumentar o número de páginas, não será, na sua essência, um artigo completo (Artigo de Pesquisa). Tampouco um artigo completo cujo texto está "enxuto" será caracterizado como uma nota científica (Nota de Pesquisa), pois sua essência não é a mesma. Portanto, apesar de, em geral, artigos completos serem mais extensos que notas científicas, não é o número de páginas que define o que é um e o que é outro.

Artigo de revisão, por sua vez, não se resume à apresentação (ou reunião) do conhecimento científico gerado até o momento em um único artigo. Estruturalmente, artigos de revisão são similares a artigos completos ou notas científicas, apresentando a justificativa, o objetivo, a metodologia, os resultados (que se referem ao conhecimento gerado até o momento), a discussão (que é a visão crítica do autor sobre o conhecimento gerado) e a conclusão (que é o conhecimento científico inédito gerado pelo autor, com base no conhecimento científico que se tinha até o momento). Portanto, um artigo de revisão deve gerar conhecimento científico novo, não apenas reunir informações (conhecimento) já presentes na literatura.

Outro tipo de artigo científico explorado mais recentemente é a meta-análise. Meta-análise é uma síntese de pesquisas anteriores sobre um assunto (em geral, polêmico), que apresenta ênfase na produção de conclusões quantitativas, visando extrair informação adicional de dados pré-existentes através da união de resultados de diversos trabalhos e pela aplicação de uma ou mais técnicas estatísticas (UFSM 2017). Meta-análise não é derivada de uma pesquisa original, mas sim da análise de pesquisas já publicadas, e, portanto, é incluída como Artigo de Revisão.

Espera-se, em conclusão, que as dúvidas a respeito dos artigos publicados pela Revista de Ciências Agroveterinárias tenham sido sanadas e que esta breve nota auxilie a redação de futuros trabalhos a serem submetidos e publicados nesta revista.

Universidade Estadual Paulista, Jaboticabal, SP, Brasil.

Autor para correspondência <lbcarvalho@fcav.unesp.br> 


\section{REFERÊNCIA}

UFSM - Universidade Federal de Salta Maria. 2017. Modelagem Animal. Disponível em: <http://w3.ufsm.br/modelanimal/ index_arquivos/page0002.htm>. Acesso em: 21 jul. 2017. 